\title{
First report of detection of IgA anti-Acanthamoeba antibodies among Saudi population and amoeba isolation from their surroundings
}

\author{
Alouffi, A.S. ${ }^{1,4}$, Dawoud, T.M. ${ }^{2}$, Almaary, K.S. ${ }^{2}$, Mubarak, A.S. ${ }^{2}$, JarAllah, K. ${ }^{3}$, Matin, A. ${ }^{{ }^{*}}$ \\ ${ }^{1}$ College of Arts and Sciences, Department of Biological Sciences and Chemistry, University of Nizwa, Birkat Al-Mouz, Nizwa, 616, Sultanate of Oman \\ ${ }^{2}$ Botany and Microbiology Department, Science College, King Saud University, PO Box 2455, Riyadh, 11451, Saudi Arabia \\ ${ }^{3}$ Department of Medical Laboratory Sciences, College of Applied Medical Sciences, Majmaah University, Majmaah 11952, Saudi Arabia \\ ${ }^{4}$ King Abdulaziz City for Science and Technology, Riyadh, Saudi Arabia \\ *Corresponding author: amawan@live.co.uk; abdulmatin@unizwa.edu.om
}

\section{ARTICLE HISTORY}

Received: 14 September 2020 Revised: 3 December 2020 Accepted: 4 December 2020 Published: 25 March 2021

\begin{abstract}
Acanthamoeba is an opportunistic protozoan pathogen which is found in diverse environment worldwide. Being ubiquitous nature of this amoeba we come across it in our daily life. Acanthamoeba species are recognized as human pathogens; that may cause blinding keratitis and rare but fatal granulomatous encephalitis involving central nervous system. To date, there is not a single report in literature demonstrating anti-Acanthamoeba antibodies among the Saudi population, and thus aim of the present study. Using ELISA, we identified the antibody level in the local population. Our results represent the secretory IgA antiAcanthamoeba in mucosal secretions from 133 individuals aged 15-60 years. The antiAcanthamoeba antibody prevalence rate was $>80 \%$, and no considerable differences were observed between prevalence in males $(80.28 \%)$ and that in females (80.64\%). In addition, environmental sources (soil and water) from the environment of the participants in our study were evaluated for amoeba incidence. The amoeba was identified by morphological characteristics of cysts or trophozoites on non-nutrient agar plates grown with $E$. coli. Overall, $58.75 \%$ of samples from water and $32.85 \%$ of those from soil were culture positive for outgrowth of amoeba on non-nutrient agar plates. Furthermore, PCR was carried out with genus-specific primers to confirm the presence of Acanthamoeba DNA. Our results revealed that about $68 \%$ of cultures from water and $43 \%$ of those from soil were successfully amplified and proved to be amoeba DNA. Interestingly, a few samples yielded more than one product, which suggests that some other amoebic species may be present in the same sample (MAC-W1 and MADW1). To the best of our knowledge, we described for the first time the amoeba isolation from the participant's close environment and antibodies level among Saudi population. Our future studies will be focused on additional molecular characterization of isolated amoeba and their pathogenic potential which could be a possible threat for the community.
\end{abstract}

Keywords: Acanthamoeba, IgA, Saliva samples, Isolation, Epidemiology, Prevalence, Protozoa, Saudi Arabia.

\section{INTRODUCTION}

Free-living amoebae that belong to the genus Acanthamoeba are opportunistic protozoan organisms that are distributed worldwide. The amoeba has been discovered in various media of air, soil and water across the globe; therefore, it plays a pivotal role in the environment. Some Acanthamoeba species cause severe and deadly human infections, an example of which is a chronic granulomatous infection that involves the central nervous system (CNS) and occurs among immunocompromised individuals which always leads to death (Visvesvara et al., 2007). More than 200 granulomatous amoebic encephalitis (GAE) cases caused by Acanthamoeba spp. have been reported worldwide, but none from the
Kingdom of Saudi Arabia to date (Schuster \& Visvesvara, 2004). Acanthamoeba also causes disseminated infections including in the skin, sinuses, lungs, prostate, and uterus (Marciano-Cabral \& Cabral, 2003). Furthermore, Acanthamoeba trigger keratitis (a painful infection of the eye which leads to blindness) mostly associated with contact lens wearers (Verani et al., 2009; Panjwani, 2010; Niederkorn, 2020). Acanthamoeba species have become increasingly recognized as important microbes. Infections caused by Acanthamoeba have gained attention over the years due to their presence in the ecological habitat (Rezaeian et al., 2008; Liang et al., 2010), their direct connection with humans on a daily basis, and their accountability for human diseases (Anisah et al., 2005; Ledee et al., 2009). The number of infections has 
increased, probably because of increasing numbers of contact-lens wearers, increasing populations of immunocompromised patients, and global warming that has caused the amoeba to flourish. Of the hundreds of infections that have been caused by Acanthamoeba, only a few victims have survived because of delays in diagnosis due to lack of knowledge and poor empirical treatment due to lack of optimal therapy.

Due to the widespread nature of Acanthamoeba, it is speculated that most people have developed antibodies against this organism. Two studies have been demonstrated the incidence of anti-Acanthamoeba antibody titres from healthy populations (Cursons et al., 1980; Cerva, 1989). Of these studies, the Cerva research, which was conducted in New Zealand, shows that normal human sera possess antibodies in the ratios of 1:20 to 1:80 titres for Acanthamoeba spp from $100 \%$ of individuals tested (Cerva, 1989). On the other hand, of the participants in one investigation conducted in Bohemia, Czechoslovakia, it was discovered that only nine (3.2\%) were seropositive (Cursons et al., 1980). Furthermore, 448 patients in a Prague hospital were investigated and $41(9.1 \%)$ were found to be positive (Cursons et al., 1980). Among patients with CNS disorders at a psychiatric hospital, nine (3.3\%) of 274 patients were reported to be positive and possessed the highest titres of positive sera at $1: 160$. Of note, $26(52 \%)$ of 50 hepatitis $A$ patients were observed to be positive for Acanthamoeba, with the highest titres of positive sera being 1: 640 (Cursons et al., 1980).

Overall, these findings reveal the contradictory nature of human contact with Acanthamoeba. Later studies tested for the presence of Acanthamoeba antibodies among 43 healthy individuals and 25 Acanthamoeba keratitis patients (Alizadeh et al., 2001; Walochnik et al., 2001). It is of note that all tested individuals were seropositive for Acanthamoeba; however, the keratitis patients confirmed considerably lower levels of slgA compared with the healthy subjects. Here, we report our investigations into the level of anti-Acanthamoeba antibodies within the hitherto unexplored Saudi population, along with the prospects of isolation of Acanthamoeba from the surrounding environment of those who took part in our study.

\section{MATERIALS AND METHODS}

\section{Acanthamoeba cultures}

A clinical isolate of Acanthamoeba castellanii belonging to T4 genotype, isolated from a keratitis patient (American Type Culture Collection, ATCC 50492) was used in the present study. T4 genotype is considered to be the highly prevalent in the environment (Niyyati et al., 2009) and known to be the more frequently amplified in the laboratory conditions than other genotypes (Kawaguchi et al., 2009); thus chosen for the present investigation. Acanthamoeba castellanii trophozoites were grown without shaking in $15 \mathrm{ml}$ of PYG medium [proteose peptone $0.75 \%(\mathrm{w} / \mathrm{v})$, yeast extract $0.75 \%(\mathrm{w} / \mathrm{v})$ and glucose $1.5 \%(\mathrm{w} / \mathrm{v})$ ] in $\mathrm{T}-75$ tissue culture flasks at $30^{\circ} \mathrm{C}$ and the media was refreshed 17-20 h prior to experiments as previously described (Imran et al., 2016; Rafique et al., 2020). This resulted in more than $99 \%$ amoebae in the trophozoite forms, which were subsequently used in experiments.

\section{Collection of environmental samples from the participants' surroundings}

Environmental samples were collected from the study participants' close environment (water from bathrooms, kitchens and mosques; soil from gardens and potted plants), using sterile polypropylene bottles and bags respectively, from June 2016 to July 2018. All sealed packed samples were tagged with the time, date, type and site of collection and stored at $4^{\circ} \mathrm{C}$ until used as described previously (Tanveer et al., 2015).

\section{Acanthamoeba isolation using plating assays}

For Acanthamoeba isolation, plating assays were performed as described previously (Lorenzo-Morales et al., 2006; Tanveer et al., 2013). Briefly, bacteria were grown in Luria-Bertini (LB) media, containing $1 \%(\mathrm{w} / \mathrm{v})$ tryptone, $0.5 \%(\mathrm{w} / \mathrm{v})$ yeast extract, and $1 \%(\mathrm{w} / \mathrm{v}) \mathrm{NaCl}$ overnight, and heat killed as described previously (Tanveer et al., 2013). Heat-killed bacteria were transferred on to non-nutrient agar plates and left for 2-3 minutes. The surplus cultures were removed and plates left to dry. Water samples $(50 \mathrm{~mL})$ were filtered through the nitrocellulose membrane (pore size: $0.2 \mu \mathrm{M}$ ) and filters were placed inverted on $1.5 \%$ non-nutrient agar (NNA) plates that housed an E. coli lawn. Plates were kept at $30^{\circ} \mathrm{C}$. Plates were incubated while sealed in plastic bags to prevent dehydration and investigated with an inverted microscope. Subsequently amoebae were detected that were nourished by $E$. coli on NNA; segments of the agar that contained these amoebae were removed and relocated onto new bacteria-coated plates. After the amoebae of interest had been separated from fungal and other contaminants, they were relocated in agar cores to fresh, bacteria-lawn agar plates. Next, the plates were observed for out-growth of Acanthamoeba (either cysts or trophozoites or both) microscopically for up to two weeks. In contrast, soil samples $(2 \mathrm{~g})$ were weighted and suspended in $20 \mathrm{~mL}$ of sterile distilled water and the soil particles were allowed to settle in the tube. Furthermore, water sample $(150 \mu \mathrm{L})$ was taken from the tube and inoculated onto $1.5 \%$ NNA plates, as described before (Lorenzo-Morales et al., 2006; Tanveer et al., 2015).

\section{DNA extraction}

Amoebae were scraped from the NNA plates, and DNA extraction was carried out as described before (Matin et al., 2006; Tanveer et al., 2015). Briefly, amoebae were washed $3 x$ in PBS ( $\mathrm{pH} \mathrm{7.4)} \mathrm{and} \mathrm{resuspended} \mathrm{in} 500 \mu \mathrm{L}$ of cell lysis buffer $(100 \mathrm{mM} \mathrm{KCl}, 40 \mathrm{mM}$ Tris, $25 \mathrm{mM} \mathrm{MgCl}$, $1 \%$ Tween-20, and $0.1 \mathrm{mg} / \mathrm{mL}$ proteinase $\mathrm{K}$ ). After gentle mixing by inversion, the lysates were incubated at $56^{\circ} \mathrm{C}$ for $3 \mathrm{~h}$. These samples were chilled on ice for $5 \mathrm{~min}$ and were extracted with equal volumes of phenol-chloroform (1:1). After extraction, the aqueous and organic phases were separated by centrifugation at $15,000 \mathrm{rpm}$ for $15 \mathrm{~min}$ at room temperature (RT). Next, the supernatant was extracted with an equal volume of chloroform-isoamyl alcohol (24:1). After centrifugation at $15,000 \mathrm{rpm}$, the upper aqueous phase was collected and DNA was precipitated by adding 1/10 volume of $10 \mathrm{M}$ ammonium acetate plus two volumes of cold absolute ethanol and kept at $-20^{\circ} \mathrm{C}$ overnight. The DNA was precipitated by centrifugation at $15,000 \mathrm{rpm}$, after washing with $100 \mu \mathrm{L}$ of $70 \%$ ethanol, then dried at RT, dissolved in $300 \mu \mathrm{L}$ of doubledistilled water, and stored at $-20^{\circ} \mathrm{C}$ until used.

\section{Amplification by polymerase chain reaction}

The DNA amplification was carried out using genus-specific primers as described previously (Booton et al., 2002; Matin et al., 2006; Tanveer et al., 2013). Primer pairs include the forward primer JDP1 (5-GGCCCAGATCGTTTACCGTGAA) and the reverse primer JDP2 (5-TCTCACAAGCTGCTAGGGAGTCA). Polymerase chain reactions (PCRs) were executed in a $20 \mu \mathrm{L}$ volume that contained $1.25 \mathrm{U}$ Taq polymerase, 0.2-0.4 $\mu \mathrm{g}$ DNA, $200 \mu \mathrm{M}$ 
dNTPs, $2 \mathrm{mM} \mathrm{MgCl}$, and $2 \mu \mathrm{M}$ primer, at $95^{\circ} \mathrm{C}$ for $5 \mathrm{~min}$ for one cycle, $94^{\circ} \mathrm{C}$ for $1 \mathrm{~min}, 60^{\circ} \mathrm{C}$ for $1 \mathrm{~min}$, and $72^{\circ} \mathrm{C}$ for $2 \mathrm{~min}$ for 35 cycles. There was a final elongation step of $10 \mathrm{~min}$ at $72^{\circ} \mathrm{C}$. Amplified DNA was electrophoresed on $2 \%$ agarose gels, stained with ethidium bromide, and visualised under ultraviolet light.

Detection of antibodies using enzyme-linked immunosorbent assays

The presence of anti-Acanthamoeba sIgA in mucosal secretions (saliva samples collected from healthy volunteer persons) was established using enzyme-linked immunosorbent assays (ELISA) as described previously (Brindley et al., 2009; Matin et al., 2012). Briefly, Acanthamoeba (50,000 amoebae per $0.2 \mathrm{~mL} /$ well) were inoculated in PYG growth medium in a 96 -well plate at $30^{\circ} \mathrm{C}$ for $24 \mathrm{~h}$. Consequently, the wells were air dried, and then ice cold methanol and acetone (1:1) were added for $45 \mathrm{~min}$. The wells were washed twice with PBS (containing $0.05 \%$ Tween-20) to eliminate nonadherent amoebae and blocked using 3\% bovine serum albumin for $1 \mathrm{~h}$ at $37^{\circ} \mathrm{C}$. Saliva samples were obtained from 133 asymptomatic participants, and stored at $4^{\circ} \mathrm{C}$ until tested. The saliva samples were serially diluted from 1:1 to 1:100. The wells were rinsed and $100 \mu \mathrm{L}$ of test samples were added to wells and incubated for $18 \mathrm{~h}$ at $4^{\circ} \mathrm{C}$. The subsequent day, amoebae were rinsed $3 \times$ with PBS plus Tween-20 and wells were incubated with mouse anti-human IgA antibody (Abcam, Cambridge, UK). The plates were incubated for $60 \mathrm{~min}$, after which the wells were rinsed again $3 \times$ as described above. Next, anti-mouse IgG antibody conjugated to horseradish peroxidase was placed in all wells. The plates were incubated for $1 \mathrm{~h}$ at $37^{\circ} \mathrm{C}$. Finally, the wells were rinsed $3 \times$ as described above and $100 \mu \mathrm{L}$ of substrate solution $\left(0.1 \% \mathrm{H}_{2} \mathrm{O}_{2}\right.$ and $0.1 \%$ orthophenylenediamine in citrate buffer) was added. The reactions were permitted to develop for $15 \mathrm{~min}$ and finally $100 \mu \mathrm{L}$ of $3 \%$ sulphuric acid was added to stop the reaction. The optical density of each well was established on a microplate reader at $492 \mathrm{~nm}$. The optical density of Acanthamoeba incubated with secondary antibody in the absence of saliva samples was measured as a background. Acanthamoeba seroprevalence is defined here as saliva reacting with Acanthamoeba castellanii of the T4 genotype with an optical density above the background values.

\section{RESULTS}

\section{ELISA detects Acanthamoeba-specific slgA in mucosal secretions} of Saudi population

To establish the presence of anti-Acanthamoeba slgA in saliva samples, ELISA was performed as described in Materials and Methods. A total of 133 samples were collected from healthy residents of Saudi Arabia. The participants' ages varied from 16 to 65 years. The age and gender characteristics are shown in Table 1. The overall prevalence of Acanthamoeba was $80.64 \%$ in females and $80.28 \%$ in males. There was no significant difference in the findings between genders $(P>$ 0.05 , using paired $T$ test, one tail distribution). The antiamoeba antibodies prevalence was observed approximately $85 \%$ in the saliva samples of Saudi population among 16-29 age range which was increased to $100 \%$ among 30 years of age and onwards.

Acanthamoeba isolated from the nearby surroundings of all subjects tested

To find the level of common contact of the Saudi population with Acanthamoeba, ecological samples taken from participants' surroundings were evaluated. These were tested to discover the incidence of Acanthamoeba, as described in Materials and Methods. On the basis of morphological characteristics of cysts or trophozoites, amoebae from the genus Acanthamoeba were recognized as positive (as shown by outgrowth of protozoa) from water samples on NNA plates after seven to 14 days of incubation when examined visually under an inverted microscope. The detached amoebae were preserved and decontaminated by sporadic cutting of a small piece of agar that contained cysts or trophozoites and transplanting it to a fresh NNA plate coated in a heat-killed bacteria lawn. Overall, 47 out of 80 (58.75\%) samples from water and 23 out of 70 (32.85\%) from soil were culture positive for outgrowth of amoebae on NNA plates (representative examples are displayed in Figure 1).

PCR amplification confirms existence of Acanthamoeba DNA in both soil and water samples

To further verify the presence of amoebae population on NNA plates, DNA was obtained from the scrapings acquired from NNA plates and exploited for PCR reactions using Acanthamoeba genus-specific JDP1 and JDP2 primers, as described in Materials and Methods. Most of the samples yielded a sole PCR product of fewer than $500 \mathrm{bp}$, which validated the existence of Acanthamoeba DNA. Interestingly, a few samples yielded more than one PCR product, which suggests that some other amoebic species may have been present in the same sample (MAC-W1 and MAD-W1). Our results revealed that 32 of $47(68.08 \%)$ samples from water and 10 of $23(43 \%)$ from soil were fruitfully amplified.

\section{DISCUSSION}

The genus Acanthamoeba belongs to a free-living amoeba family that has become progressively more distinguished as an important microscopic organism in recent years. Acanthamoeba are well known as human pathogens that may cause serious and fatal infections. The number of Acanthamoeba infections has escalated worldwide due to the existence of this amoeba in the normal ecosystem (Rezaeian et al., 2008; Liang et al., 2010; Latifi et al., 2020) and its direct association with humans in everyday life and is responsible for human diseases (Anisah et al., 2005; Ledee et al., 2009). The increasing number of infections is most probably due to escalating statistics of contact-lens wearers, mounting populations of immunocompromised patients and the rise of global warming which aids the growth of the amoebae. Infections caused by Acanthamoeba have been

Table 1. Prevalence by age of anti-Acanthamoeba castellanii (T4 genotype) antibodies among males and females of the study cohort. Total number of subjects surveyed is shown in bracket

\begin{tabular}{ccc}
\hline Age & Males & Females \\
\hline $16-19$ & $30(34)$ & $24(27)$ \\
$20-24$ & $8(10)$ & $7(8)$ \\
$25-29$ & $2(3)$ & $2(2)$ \\
$30-34$ & $3(4)$ & $1(3)$ \\
$35-39$ & $2(2)$ & $2(3)$ \\
$40-44$ & $2(4)$ & $2(3)$ \\
$45-49$ & $2(2)$ & $1(1)$ \\
$50-54$ & $2(2)$ & $1(1)$ \\
$55-59$ & $1(2)$ & $2(2)$ \\
$60+$ & $1(1)$ & $1(1)$ \\
NA & $4(7)$ & $7(11)$ \\
Total & $57(71)$ & $50(62)$ \\
\hline
\end{tabular}


Table 2. Acanthamoeba isolation on non-nutrient agar plates from surrounding environments of the participants, amoebic DNA confirmation through PCR and antibody prevalence via ELISA of the representative areas of Saudi Arabia

\begin{tabular}{|c|c|c|c|c|c|c|c|c|}
\hline \multirow[t]{2}{*}{ S. No } & \multicolumn{2}{|c|}{$\begin{array}{l}\text { Sampling from participant's } \\
\text { close environment with } \\
\text { sampling codes }\end{array}$} & \multirow[t]{2}{*}{ Sampling area } & \multicolumn{2}{|c|}{$\begin{array}{l}\text { Amoebic } \\
\text { outgrowth on } \\
\text { NNA Plates }\end{array}$} & \multicolumn{2}{|c|}{ PCR } & \multirow{2}{*}{$\begin{array}{l}\text { Level of antibodies } \\
\text { detection from } \\
\text { participant's saliva }\end{array}$} \\
\hline & Water & Soil & & Water & Soil & Water & Soil & \\
\hline 1 & $\mathrm{ABH}-\mathrm{W} 3$ & $\mathrm{ABH}-\mathrm{S} 4$ & Abha & + & + & + & + & +++ \\
\hline 2 & BIDH-W1 & BIDH-S2 & Buraidah & - & - & - & - & + \\
\hline 3 & DAM-W5 & DAM-S1 & Dammam & + & + & + & - & ++ \\
\hline 4 & KAJ-W1 & KAJ-S3 & Al Kharj & - & - & - & - & + \\
\hline 5 & KHR-W4 & KHR-S6 & Khobar & + & + & + & - & ++ \\
\hline 6 & HAI-W2 & HAI-S5 & Hail & + & + & + & - & ++ \\
\hline 7 & HAR-BAT-W3 & HAR-BAT-S1 & Harar Al-Batin & + & + & - & - & ++ \\
\hline 8 & HOF-W4 & HOF-S2 & Al Hofuf & + & - & - & - & ++ \\
\hline 9 & JAF-W7 & JAF-S3 & Jawf & - & - & - & - & + \\
\hline 10 & JAZN-W2 & JAZN-S1 & Jazzan & + & + & + & - & +++ \\
\hline 11 & JEDH-W3 & JEDH-S2 & Jeddah & + & - & + & + & +++ \\
\hline 12 & MAJ-W2 & MAJ-S5 & Majmaah & - & - & - & - & ++ \\
\hline 13 & MAD-W1 & MAD-S2 & Madina & + & + & + & + & +++ \\
\hline 14 & MAC-W1 & MAC-S1 & Mecca & + & + & + & + & +++ \\
\hline 15 & NAJ-W1 & NAJ-S2 & Najran & + & - & - & - & ++ \\
\hline 16 & QAS-W1 & QAS-S1 & Qaseem & + & + & + & + & +++ \\
\hline 17 & RIYH-W3 & RIYH-S4 & Riyadh & - & + & - & - & ++ \\
\hline 18 & TABK-W4 & TABK-S7 & Tabuk & + & + & + & - & +++ \\
\hline 19 & TAF-W6 & TAF-S3 & Taif & - & + & - & - & ++ \\
\hline 20 & ZUL-W3 & ZUL-S2 & Al Zulfi & - & - & - & - & + \\
\hline
\end{tabular}

Frequency of antibody level: Rare: +; Medium: ++; Significant: +++.

reported worldwide, but not previously from Saudi Arabia, perhaps due to lack of knowledge and expertise.

Until now, there has been no documentented proof of Acanthamoeba infection reported from the Gulf region (including Bahrain, Kuwait, Oman, Qatar, Saudi Arabia and the United Arab Emirates) except from Oman, where two Acanthamoeba keratitis cases have been reported so far (AlKharousi \& Wali, 2009, 2012). Due to lack of expertise on this pathogen and lack of knowledge regarding this amoeba and disease, it may have gone unnoticed. Knowing the free-living characteristics of this organism, it is likely that humans interact with Acanthamoeba in their routine daily lives. However, it has been observed that keratitis caused by Acanthamoeba is frequently misdiagnosed as a herpes simplex adenovirus or other viral infection (Hammersmith, 2006).

To date there has been no documented evidence available in the literature which demonstrates the antiAcanthamoeba antibody level among the Saudi population. For this purpose a noninvasive approach (slgA in saliva) was adopted in this investigation and ELISA was carried out to establish the existence of anti-Acanthamoeba antibodies. It is worth mentioning that most of the participants involved in this study had undertaken at least one trip abroad (to the UK, USA or Europe) either for tourism or study and at least one trip to Makkah and Madina to perform Hajj or Ummarah. Saudi inhabitants consume filtered, bottled, mineral water which is free from pollutants (data not shown); however, the whole population uses untreated tank water to perform ablutions at least five times a day, and this could enable the interaction of this amoeba with the Saudi population either though the mouth or nose. This would explain the finding that all the participants over the age of 30 possessed antibodies against this amoeba, suggesting the local population have developed antibodies which ultimately protects from amebic infection as described previously (Leher et al., 1999).
Overall, the present study disclosed a high frequency (87.7\%) of anti-Acanthamoeba antibodies, to a similar degree in males (80.28\%) as females (80.64\%). Acanthamoeba were also found in samples taken from the participants' close environment. This finding endorses the free-living nature of these pathogens to which we are exposed in our everyday lives. It has been shown that more than $80 \%$ of the healthy human population exhibits antibodies against Acanthamoeba (Chappell et al., 2001), suggesting that these organisms often come into contact with humans.

Our previous investigation to determine the presence of anti-Acanthamoeba antibodies among the population of Pakistan showed the highest prevalence among the tribal population of Khyber Pakhtunkhwa as compared with the rest of the country (Matin et al., 2012). Acanthamoeba has also been isolated from various environmental sources (soil and water) across Pakistan (Tanveer et al., 2013, 2015). In Pakistan, the majority of the population use spring water or municipal water, as the majority cannot afford mineral/bottled water, and this could mean that the population comes across this amoeba on a daily basis. Also, Pakistan is an agricultural country; $>70 \%$ of the population is engaged with agriculture, which also leads to frequent contact with this amoeba. In contrast, in another report, heterogeneous populations of 114 subjects from 37 countries and six continents were studied in the United Kingdom (Brindley et al., 2009). Of these 114 individuals, 100 were found to test positive for the presence of slgA, an overall prevalence of $87.7 \%$ from all continents tested. The high prevalence of the Acanthamoeba antibody in ethnically and racially diverse populations suggests that (i) people come across these pathogens frequently in their normal surroundings and (ii) few diseases are caused by this organism (Brindley et al., 2009). Similarly, in the present investigation, of 133 participants recruited from the Kingdom of Saudi Arabia, 107 were found to be positive for the presence of slgA, an overall prevalence of $80.45 \%$ from all regions tested. Notably, the participants from 
(A)

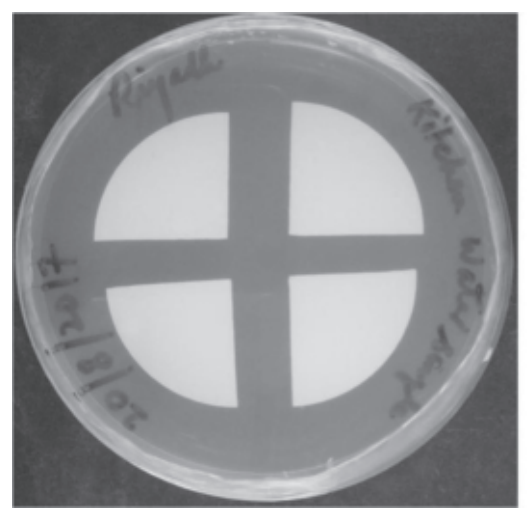

\section{Labeled information on \\ Plate A: Water sample}

Sampling collection site: Riyadh

Water source: Kitchen Water

Date of sampling: 20/08/2017
(B)

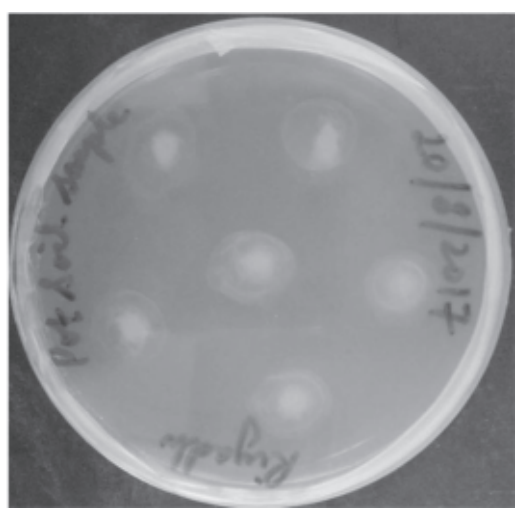

Labeled information on

Plate B: Soil sample

Sampling collection site: Riyadh

Soil source: In house Pot

Date of sampling: 20/08/2017

(C)

Water samples

Soil samples
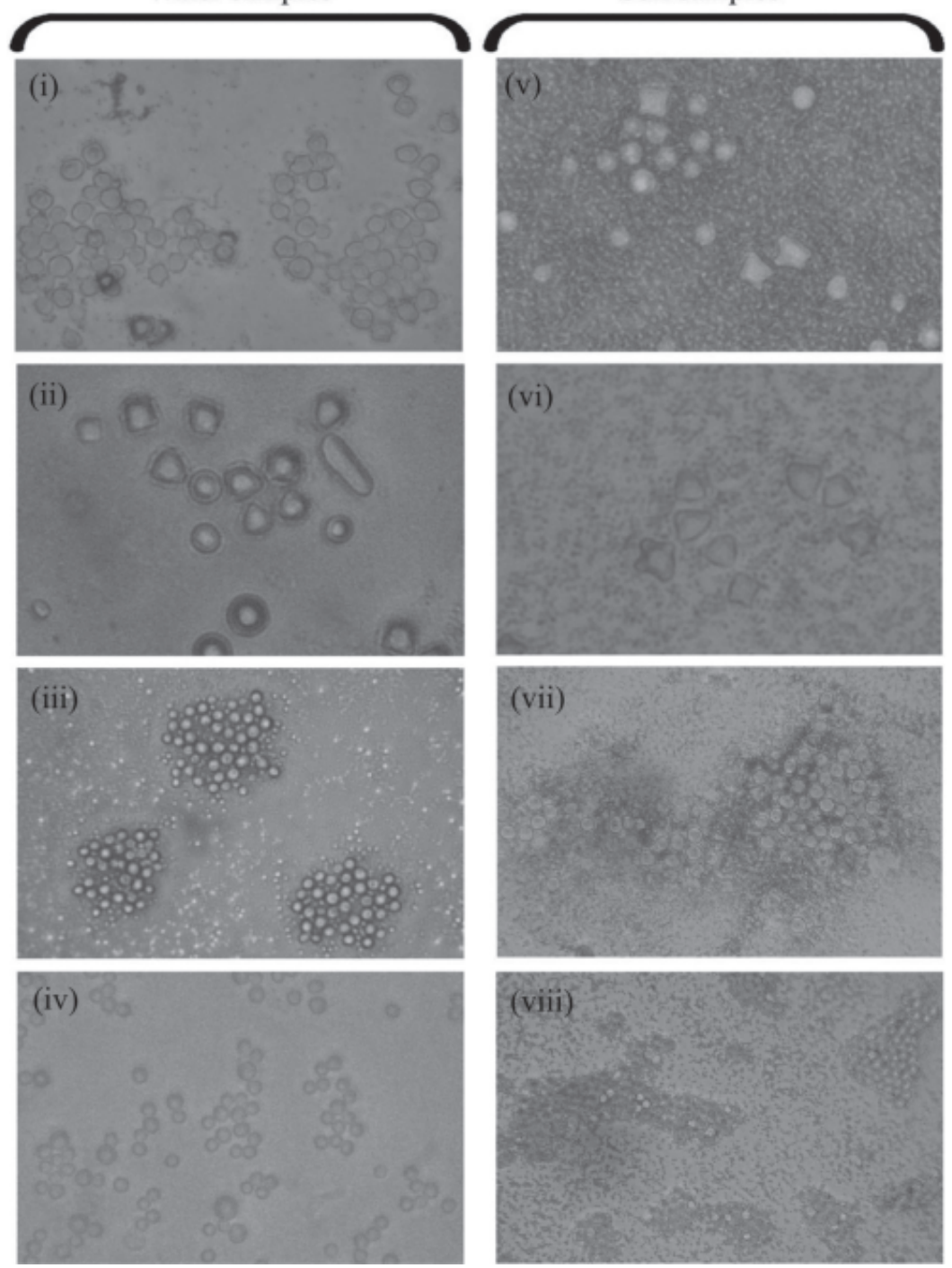

Figure 1. (a) A water sample $(500 \mathrm{~mL})$ was systematically stirred and filtrated via a cellulose nitrate filter and harvested on an NNA plate bedded with heat-killed E. coli as described in Materials and Methods. (b) Soil samples (2g) were suspended in $20 \mathrm{ml}$ of sterile distilled water and $150 \mu \mathrm{L}$ of each sample was harvested onto NNA plates, as described in the Materials and Methods section. (c) Amoebic plaque was morphologically observed on NNA plates under an inverted microscope. Plates were observed for outgrowth for up to 14 days and images $(\times 400)$ taken. Images of representative water samples: (i). MAC-W1; (ii). JAZN-W2; (iii). MAD-W1; (iv). ABH-W3 and soil samples (v). QAS-S1; (vi). TABK-S7; (vii). HAR-BAT-S1; (viii). HAI-S5 are shown here. 
Makkah and Madina were shown to have the maximum antibody level and amoebae were isolated from both environmental sources (soil and water) of the participants' surroundings.

The existence of free-living amoeba in environmental sources (soil and water) of Saudi Arabia is not surprising as it has been reported in the past (Al-Herrawy \& Al-Rasheid, 1998; Toula et al., 2017). These two studies did not demonstrate much information regarding the prevalence of the amoeba in the Saudi environment. However, millions of Muslims visit Makkah and Madina for Hajj and Ummarah each year, and this could lead to the transmigration of different amoeba species from different countries to Saudi. Furthermore, thousands of animals are imported for slaughter from different countries to Makkah during the Hajj. So transportation of the amoeba through animals could also occur. Amoebic meningoencephalitis has been shown in sheep (Van der Lugt \& Van der Merwe, 1990). Our research group has studied free-living amoeba since 2005; our interests are to explore the diverse environmental sources of the country to understand the epidemiology of the organism in this part of the world. Such studies have been carried out in the UK, Pakistan and Saudi Arabia. It was observed in this study that $85 \%$ of samples collected from Saudi Arabia showed growth on NNA plates that resembled morphologically the amoebic cysts, but when the same outgrowth from NNA plates was tested through amplification using Acanthamoeba genus-specific primers, only 42 out of 70 (60\%) could be established as Acanthamoeba. This could be because of various factors. It is rational to expect that the non-amplified products might indicate the incidence of other protozoan cysts, since an earlier study (Arnalich-Montiel et al., 2013) has demonstrated the co-isolation of two different amoebae (Vahlkampfia and Acanthamoeba) from Spain. Further molecular recognition of the cysts indicated in our study could be the subject of further research.

\section{CONCLUSION}

To the best of our knowledge, this is the first comprehensive report across the Kingdom demonstrating the level of antiAcanthamoeba antibodies among the Saudi population, along with isolation of amoeba from the participants' close environment (soil and water). Our current study suggests that there is an urgent need to investigate other natural/ ecological resources (air, soil and water) of the Kingdom to assess the current status of FLA (Acanthamoeba, Balamuthia, Naegleria and Sappinia), which may pose potential health threats in future. Furthermore, analysis of the isolated amoeba during this investigation is essential in order to establish their molecular identification, pathogenic potential and role in our surrounding environment. Our future studies will also be focussed on the exploration of role of environmental factors (i.e., temperature, $\mathrm{pH}$, salt or mineral concentration, water \& soil quality and other microbial community) which supports Acanthamoeba to withstand hard natural conditions and disseminate in our natural ecosystem.

\section{List of abbreviations}

bp: Base pair; CNS: Central nervous system; DNA: Deoxyribonucleic acid; dNTP: Deoxyribonucleotide triphosphate; ELISA: Enzyme-linked immunosorbent assays; E. coli: Escherichia coli; FLA: Free-living amoebae; GAE: Granulomatous amoebic encephalitis; IgA: Immunoglobulin A; IgG: Immunoglobulin G; ITS: Internal transcribed spacers;
$\mathrm{KCl}$ : Potassium Chloride; LB: Luria-Bertini; L. pneumophila: Legionella pneumophila; MERS-CoV: Middle East Respiratory Syndrome Coronavirus; $\mathrm{MgCl}_{2}$ : Magnesium Chloride; $\mathrm{mg} / \mathrm{ml}$ : Milligram / Millilitre; $\mu \mathrm{g}$ : Microgram; mM: Mili Molar; NNA: Non-nutrient agar; PAM: Primary amoebic meningoencephalitis; PBS: Phasphate buffer saline; PCR: Polymerase chain reaction; PYG: Peptone yeast glucose; RT: Room temperature; sIgA: Secretory immunoglobulin $A ; \mu M$ : Micro molar.

\section{ACKNOWLEDGMENTS}

The authors are thankful to the students of Majmaah University for their tremendous support in communication with the local population. We also extend our thanks to the locals who kindly provided to us the required human body secretions and nearby environmental water and soil samples for this study. Initially, there were many issues during sample and information collection due to local cultural values and the inability of the residents to communicate in English. The students helped with communication, convinced the reluctant residents to offer samples and transported the samples in a timely and well-managed manner to the laboratory. There were fewer difficulties in the big cities such as Riyadh and Jeddah, where the people were very supportive and accommodating of our wishes. There were many discussions with the Saudi people regarding the benefits of such studies; since such studies have not been conducted in the kingdom in the past, it was difficult to communicate and convince the community of the worth of such research. In this regard 30 male students from Majmaah, Hautat Sudair and Zulfi campuses and seven female students were involved in this study. The details of the students are not disclosed at their request. These students are still involved in some of the other projects that are underway.

\section{Competing Interests:}

The authors declare that they have no competing interests.

\section{REFERENCES}

Al-Herrawy, A.Z. \& Al-Rasheid, K.A. (1998). Identification of Acanthamoeba strains isolated from a freshwater course in Saudi Arabia. Journal of Egypt Public Health Association 73(5-6): 621-633.

Al-Kharousi, N. \& Wali, U.K. (2012). Confoscan: An ideal therapeutic aid and screening tool in Acanthamoeba Keratitis. Middle East African Journal of Ophthalmology 19(4): 422-425. https://doi.org/10.4103/0974-9233.102766

Al-Kharousi, N.S. \& Wali, U.K. (2009). Culture negative confoscan positive Acanthamoeba Keratitis; A relentless course. Sultan Qaboos University of Medical Journal 9(3): 338340.

Alizadeh, H., Apte, S., El-Agha, M.S., Li, L., Hurt, M., Howard, K., Cavanagh, H.D., McCulley, J.P. \& Niederkorn, J.Y. (2001). Tear IgA and serum IgG antibodies against Acanthamoeba in patients with Acanthamoeba keratitis. Cornea 20: 622-627. https://doi.org/10.1097/00003226-200108000-00013

Arnalich-Montiel, F., Lorenzo-Morales, J., Irigoyen, C., MorcilloLaiz, R., López-Vélez, R., Muñoz-Negrete, F., Piñero, J.E. \& Valladares, B. (2013). Co-isolation of Vahlkampfia and Acanthamoeba in Acanthamoeba-like Keratitis in a Spanish population. Cornea 32(5): 608-614. https://doi.org/10.1097/ ICO.0b013e31825697e6 
Anisah, N., Amal, H., Kamel, A.G., Yusof, S., Noraina, A.R. \& Norhayati, M. (2005). Isolation of Acanthamoeba sp. from conjunctival sac of healthy individuals using swab. Tropical Biomedicine 22: 11-14.

Booton, G.C., Kelly, D.J., Chu, Y.W., Seal, D.V., Houang, E., Lam, D.S.C., Byers, T.J. \& Fuerst, P.A. (2002). 18S ribosomal DNA typing and tracking of Acanthamoeba sp. isolates from corneal scrape specimens, contact lens, lens cases, and home water supplies of Acanthamoeba keratitis patients in Hong Kong. Journal of Clinical Microbiology 40: 1621-1625. https://doi.org/10.1128/JCM.40.5.1621-1625.2002

Brindley, N., Matin, A. \& Khan, N.A. (2009). Acanthamoeba castellanii: High antibody prevalence in racially and ethnically diverse populations. Experimental Parasitology 121: 254-256. https://doi.org/10.1016/j.exppara.2008.11.009

Cerva, L. (1989). Acanthamoeba culbertsoni and Naegleria fowleri: occurrence of antibodies in man. Journal of Hygiene, Epidemiology, Microbiology and Immunology 33: 99-103.

Chappell, C.L., Wright, J.A., Coletta, M. \& Newsome, A.L. (2001). Standardized method of measuring Acanthamoeba in sera from healthy human subjects. Clinical Diagnostic Laboraory and Immunology 8: 724-730. https://doi.org/10.1128/ CDLI.8.4.724-730.2001

Cursons, R.T., Brown, T.J., Keys, E.A., Moriarty, K.M. \& Till, D. (1980). Immunity to pathogenic free-living amoebae: role of humoral antibody. Infection and Immunity 29: 401-407.

Hammersmith, K.M. (2006). Diagnosis and management of Acanthamoeba keratitis. Current Opinion and Ophthalmology 17: 327-331. https://doi.org/10.1097/01.icu.0000233949. $56229.7 d$

Imran, M., Muazzam, A.G., Habib, A. \& Matin, A. (2016). Synthesis, characterization and amoebicidal potential of locally synthesized $\mathrm{TiO}_{2}$ nanoparticles against pathogenic Acanthamoeba trophozoites in vitro. Journal of Photochemistry \& Photobiology B: Biology. 159: 125-132. https://doi.org/10.1016/j.jphotobiol.2016.03.014

Kawaguchi, K., Matsuo, J., Osaki, T., Kamiya, S. \& Yamaguchi, H. (2009). Prevalence of Helicobacter and Acanthamoeba in natural environment. Letters in Applied Microbiology 48: 465471. https://doi.org/10.1111/j.1472-765X.2008.02550.x

Latifi, A., Salami, M., Kazemirad, E. \& Soleimani, M. 2020. Isolation and identification of free-living amoeba from the hot springs and beaches of the Caspian Sea. Parasite Epidemiology and Control 10: e00151. https://doi.org/10.1016/ j.parepi.2020.e00151

Leher, H., Zaragoza, F., Taherzadeh, S., Alizadeh, H. \& Niederkorn, J.Y. (1999). Monocolnial IgA antibodies protect against Acanthamoeba Keratitis. Experimental Eye Research 69(1): 75-84. https://doi.org/10.1006/exer.1999.0678

Ledee, D.R., lovieno, A., Miller, D., Mandal, N., Diaz, M., Fell, J., Fini, M.E. \& Alfonso, E.C. (2009). Molecular identification of T4 and T5 genotypes in isolates from Acanthamoeba keratitis patients. Journal of Clinical Microbiology 47: 14581462. https://doi.org/10.1128/JCM.02365-08

Liang, S.Y., Ji, D.R., Hsia, K.T., Hung, C.C., Sheng, W.H., Hsu, B.M., Chen, J.S., Wu, M.H., Lai, C.H. \& Ji, D.D. (2010). Isolation and identification of Acanthamoeba species related to amoebic encephalitis and nonpathogenic free-living amoeba species from the rice field. Journal of Applied Microbiology 109: 1422-1429. https://doi.org/10.1111/j.13652672.2010.04779.x

Lorenzo-Morales, J., Ortega-Rivas, A., Martínez, E., Khoubbane, M., Artigas, P., Victoria, P.M., Foronda, P., Abreu-Acosta, N., Valladares, B. \& Mas-Coma, S. (2006). Acanthamoeba isolates belonging to $\mathrm{T} 1, \mathrm{~T} 2, \mathrm{~T} 3, \mathrm{~T} 4$, and T7 genotypes from environmental freshwater samples in the Nile Delta region, Egypt. Acta Tropica 100: 63-69. https://doi.org/ 10.1016/j.actatropica.2006.09.008

Marciano-Cabral, F. \& Cabral, G. (2003). Acanthamoeba spp. as agents of disease in humans. Clinical Microbiology Reviews 16: 273-307. https://doi.org/10.1128/CMR.16.2.273-307.2003

Matin, A., Jeong, S.R., Faull, J. \& Khan, N.A. (2006). Evaluation of prokaryotic and eukaryotic cells as food source for Balamuthia mandrillaris. Achieve of Microbiology 186: 261271. https://doi.org/10.1007/s00203-006-0142-4

Matin, A., Ismail, M. \& Mehmood, K. (2012). Acanthamoeba castellanii; antibody prevalence among diverse tribal Pakistani population. Retrovirology 9(Supplement 1): 47. https://doi.org/10.1186/1742-4690-9-S1-P47

Niederkorn, J.Y. (2020). The biology of Acanthamoeba Keratitis. Experimental Eye Research 108365. https://doi.org/10.1016/ j.exer.2020.108365

Niyyati, M., Lorenzo-Morales, J., Rahimic, F., Motevalli-Haghia, A., Martín-Navarro, C.M., Farniaa, S., Valladares, B. \& Rezaeiana, M. (2009). Isolation and genotyping of potentially pathogenic Acanthamoeba strains from dust sources in Iran. Transaction of Royal Society of Tropical Medicine and Hygiene 103(4): 425-427. https://doi.org/ 10.1016/j.trstmh.2008.12.007

Panjwani, N. (2010). Pathogenesis of Acanthamoeba keratitis. Ocular Surface 8: 70-79. https://doi.org/10.1016/S15420124(12)70071-X

Rafique, M.W., Manan, T., Slaeem, S., Matin, A. \& Ahmad, I. (2020). Type 1 fimbriae and motility play a pivotal role during interactions of Salmonella typhimurium with Acanthamoeba castellanii (T4 Genotype). Current Microbiology 77: 836-845. https://doi.org/10.1007/s00284-019-01868-5

Rezaeian, M., Niyyati, M., Farnia, Sh. \& Haghi, A.M. (2008). Isolation of Acanthamoeba spp. from different environmental sources. Iranian Journal of Parasitology 3: 44-47.

Schuster, F.L., Honarmand, S., Visvesvara, G.S. \& Glaser, C.A. (2006). Detection of antibodies against free-living amoebae Balamuthia mandrillaris and Acanthamoeba species in a population of patients with encephalitis. Clinical Infectious Diseases 42: 1260-1265. https://doi.org/ 10.1086/503037

Schuster, F.L. \& Visvesvara, G.S. (2004). Freeliving amoebae as opportunistic and nonopportunistic pathogens of humans and animals. International Journal of Parasitology 34: 1001-1027. https://doi.org/10.1016/j.ijpara.2004.06.004

Tanveer, T., Hameed, A., Muazzam, A.G., Jung, S-Y., Gul, A. \& Matin, A. (2013). Isolation and molecular characterization of potentially pathogenic Acanthamoeba genotypes from diverse water resources including household drinking water from Khyber Pakhtunkhwa, Pakistan. Parasitology Research 112(8): 2925-2932. https://doi.org/10.1007/s00436013-3465-5

Tanveer, T., Hameed, A., Gul, A. \& Matin, A. (2015). Quick survey for detection, identification and characterization of Acanthamoeba genotypes from some selected soil and water samples in Pakistan. Annals of Agricultural and Environmental Medicine 22(2): 232-235. https://doi.org/ $10.5604 / 12321966.1152070$

Toula, F.H., Saedia, A. \& Elahl, S. (2017). Isolation and identification of free living amoeba from water sources with respect to Acanthamoeba, Naegleria in Jeddah city, Saudi Arabia. International Journal of Pharmaceutical Research and Allied Sciences 6(2): 1-8. https://doi.org/10.5455/ javar.2018.e296

Van der Lugt, J.J. \& Van der Merwe, H.E. (1990). Amoebic meningoencephalitis in a sheep. Journal of the South African and Veterinary Association 61(1): 33-36. 
Verani, J.R., Lorick, L.A., Yoder, J.S., Beach, M.J., Braden, C.R., Roberts, J.M., Conover, C.S., Chen, S., McConnell, K.A., Chang, D.C., Park, B.J., Jones, D.B., Visvesvara, G.S. \& Roy, S.L. (2009). National outbreak of Acanthamoeba keratitis associated with use of a contact lens solution, United States. Emerging Infectious Diseases 15: 1236-1242. https:// doi.org/10.3201/eid1508.090225

Visvesvara, G.S., Moura, H. \& Schuster, F.L. (2007). Pathogenic and opportunistic free-living amoebae: Acanthamoeba spp., Balamuthia mandrillaris, Naegleria fowleri, and Sappinia diploidea. FEMS Immunology and Medical Microbiology 50: 1-26. https://doi.org/10.1111/j.1574-695X.2007.00232.x

Walochnik, J., Obwaller, A., Haller-Schober, E.M. \& Aspöck, H. (2001). Anti-Acanthamoeba IgG, IgM, and IgA immunoreactivities in correlation to strain pathogenicity. Parasitology Research 87: 651-656. https://doi.org/10.1007/ s004360100412 